\title{
The Effect of Textbooks on Learning Outcome Viewed from Different Learning Motivation
}

\author{
S. P. Prasetya \\ Universitas Negeri Surabaya \\ Surabaya, Indonesia \\ sukmaperdana@unesa.ac.id
}

\begin{abstract}
This research aims to 1) examine the effect of the application of a textbook towards learning outcome, 2) examine the effect of learning motivation towards learning outcome, and 3) examine the interaction of textbooks and learning motivation towards learning outcome. This research is quasi-experimental with $2 \times 2$ factorial design. It uses ANOVA analysis of two paths. The results showed: 1) there was a significant difference in learning outcome between groups of students who studied with manual and digital textbooks $($ Fcount $=6.815 ; p=0.010), 2)$ there was a significant difference in learning outcome between groups of students who have high and low learning motivation $($ Fcount $=$ 6,$173 ; p=0.03$ ) and 3 ) there was an effect between textbooks and learning motivation interaction towards learning outcome of Learning Media of Geography $($ Fcount $=3,426 ; p=0.036)$. Thus, textbooks and learning motivation can improve learning outcome and attractiveness.
\end{abstract}

Keywords- component; Textbook; Motivation; Learning; Outcome.

\section{INTRODUCTION}

The learning result is all the effects used as an indicator of the value of using learning strategies under different conditions. Learning outcome of learners is influenced by learning strategies and characteristics of learners (Moore, 2005). It is almost the same as proposed by Dick, Carey \& Carey (2001) that the learning outcome achieved by learners is influenced by; 1) strategy or method applied in learning, 2) created learning conditions, and 3) the interaction between method and learning conditions.

More details, Degeng (1997) stated that learning strategy variables are classified into three types. First, organizing strategy, this is organizing the contents of the selected field of study for learning. Organizing activities refer to content selection activities; create charts, formatting and so on. Second, teaching strategy, i.e. a strategy to deliver message or information to learners and receive or respond to the feedback coming from learners. Third, management strategies, that is strategies to manage interactions between learners and learning variables (organizing strategies and teaching).

Associated with the teaching strategy in the form of delivering messages, materials, and information, adequate variety of learning resources are required, which could be a textbook. In the process of learning, the textbook is a very important source of learning. A textbook is all kinds of materials used to help teachers or instructors in carrying out the teaching and learning activities. Textbooks allow learners to learn coherently and systematically so that cumulatively able to master appropriate integrated learning outcome as a whole. Milligan et al., (2017); Marinkovic \& Eric (2014); Mohammadi \& Abdi (2014) asserted that textbooks provide teachers with guidance and related learning materials, such as workbooks and teacher guides, which are widely assumed to be key inputs of ineffective schooling systems and that a textbook is considered to be the means of achieving educational aims.

In this study, developed textbook is a textbook on the subject of Learning Media of Geography (LMG). The course of Learning Media of Geography (LMG) is a compulsory subject of pedagogical area that must be taken by students of Geography Education in the fifth semester. LMG is essentially an integral part of the overall learning process. LMG becomes a messenger (medium) in a variety of form that makes learning geography becomes more attractive and clear so as to improve knowledge, motivation to learn, and also help improve the quality of presentation of educators.

The textbook developed in this study consists of two versions, namely manual or printed and digital or electronic LMG textbooks. The existence of these two forms of this textbook has a lot to develop in the market, even since 2006 Kemdikbud (Ministry of Education) has spread the Electronic School Book which can be accessed free of charge by the community to improve the quality of education. On the other side, the print version of the books turned out to survive in the market, but there is no research investigating which is more effective than the use both types. According to Joo et al., (2017); Stone \& Baker-Eveleth (2013) Electronic or digital textbooks may have some alternatives that overcome the limitations of traditional paper-based books in that digital textbooks provide diverse learning resources, learning support, and customized curriculums by motivating learners and enhancing collaboration and information sharing.

Another consideration is related to the characteristics of the target (Reigeluth, 2009). Available textbooks are often not consistent with the character of learners. Some characteristics of learners who need to be observed, among others; learning motivation, learning styles, intelligence level, level of creativity, intellectual development, and so on. Therefore, educators must be careful in choosing textbooks appropriate to the characteristics of learners. Consideration of the latter is a textbook should be able to answer or solve problems or learning difficulties. 
Regeluth \& Merrill (1982) classify the learning condition variable into three groups, namely; 1) the purpose and characteristics of subjects, 2) Obstacles and subject matter catheters, and 3) the characteristics of learners. Thus, in the application of teaching strategy and material with textbooks it is recommended to note the characteristics of learners. Among some of the characteristics of learners who have been selected and is expected to affect the result of learning is the motivation to learn.

The purposes of this research are: 1). To explain the differences in learning outcome between students who use manual and digital LMG textbooks , 2). To explain the differences in learning outcome between students who have high and low learning motivation and 3). To explain the interaction between the use of textbooks and learning motivation on learning outcome.

\section{METHOD}

The method chosen in this study is a quasi-experimental design with $2 \times 2$ factorial design, i.e. a study in which two or more variables are manipulated at the same time to study the effects caused by interactions of several variables. The independent variable was the implementation learning by applying manual and digital textbook.Then the independent variable attributes (moderator) is learning motivation of students who are classified into two learning motivation, i.e. high and low learning motivation. While the dependent variable is the domain of cognitive learning outcome, as measured at the level of understanding relationship and the application skills that are classified in the taxonomy of learning Reigeluth (1999).

Subjects in this study were 73 students who took the course of learning Media of Geography in the fifth semester of the 2016/2017, Departement of Educational Geography, Faculty of Social Sciences and Law (FISH), Universitas Negeri Surabaya. To test the hypothesis of whether there is influence of textbook application on the learning outcome of LMG, the influence of motivation to learn LMG on learning outcome, and whether there were an effect of textbooks and learning motivation interaction towards learning outcome LMG, then the data were analyzed with ANOVA two paths.

\section{RESULT AND DISCUSSION}

\subsection{Result}

Hypothesis testing is done to test students' learning outcome of LMG after using LMG manual and digital LMG textbooks, and see the effect of high and low learning motivation variable and their interactions' effect. This test was conducted to validate the hypothesis. The hypothesis proposed that (1) There is a significant difference in learning outcome of LMG between students who carry manual and digital LMG textbooks (2) There are significant differences in learning outcome of LMG between students who have high and low motivation in learning (3) There is a significant effect of LMG textbooks and motivation interaction on learning outcome LMG.
Hypothesis testing is done by analyzing data of LMG achievement test. After calculation techniques of analysis with variance (ANOVA), two lines at a significance level of 0.05 with SPSS obtained results presented in Table 1 below.

Table 1. Summary Calculation Results Mechanical Analysis of VARIANCE TWO LINE

\begin{tabular}{|c|c|c|c|c|c|}
\hline Source & $\begin{array}{c}\text { Type III Sum of } \\
\text { Squares }\end{array}$ & $\mathrm{df}$ & $\begin{array}{c}\text { Mean } \\
\text { Square }\end{array}$ & $\mathrm{F}$ & Sig. \\
\hline Corrected Model & $1745.844^{\mathrm{a}}$ & 5 & 349.169 & 5.327 & .000 \\
\hline Intercept & 694443.094 & 1 & 694443.094 & $1.059 \mathrm{E} 4$ & .000 \\
\hline LMG Textbooks & 446.720 & 1 & 446.720 & 6.815 & .010 \\
\hline Motivation & 809.225 & 2 & 404.613 & 6.173 & .003 \\
\hline $\begin{array}{c}\text { Textbooks } * \\
\text { Motivation }\end{array}$ & 449.116 & 2 & 224.558 & 3.426 & .036 \\
\hline Error & 7472.523 & 68 & 65.548 & & \\
\hline Total & 709348.000 & 73 & & & \\
\hline corrected Total & \multicolumn{7}{|c|}{$9218.367 \quad 72$} & & & \\
\hline $\begin{array}{l}\text { a. } R \text { Squared }=.189 \text { (Adjusted } R \text { Squared }=.154) \\
\text { Specification F: } F_{\text {arithmetic }} \text { Sig: significance }\end{array}$ & & \\
\hline
\end{tabular}

3.1.1 Differences between Groups of Students' Learning Outcome with Manual and Digital LMG Textbooks

The calculation of LMG learning outcome data obtained the price of the Fcount $=6.815$ with level 0,010 significance. This suggests that the significance level $\alpha=0.010$ is below the $0.05(0.010<0.05)$. Thus, H0 is rejected. This means that there are significant differences between the students' LMG learning outcome using manual and digital LMG textbooks. By looking at the average learning outcome, it shows that the average of students' learning outcome using manual LMG textbooks, i.e. 78.4 , is greater than those using digital, i.e. 74.3. It can be concluded that in general those studying using manual LMG textbooks achieve the learning outcome better.

3.1.2. Difference between Students' Learning Outcome with High and Low Motivation

From the calculation result of learning outcome, material prices obtained Fcount $=6,173$ with a significance level of 0.03 . This suggests that the significance level $\alpha=0.03$ is below the $0.05(0.03<0.05)$. Thus, H0 is rejected. This means that there are significant differences between the groups LMG learning outcome of students who have high motivation (HM) and low motivation (LM) in learning. By looking at the average results, group of students who have high motivation obtain 79.19 , higher than the average student results that have a low learning motivation at 72.76 or $([\mathrm{HM}=79.19]>[\mathrm{LM}=$ 72.76]). It can be concluded that students with high motivation achieve better learning outcome than those with low motivation.

3.1.3 The Effect of Interaction between Textbooks and Motivation towards LMG Learning Outcome

From the calculation of LMG learning outcome, the effect of the interaction between LMG textbooks and learning motivation of students on the learning outcome obtained the price of $F=3,426$ with significance level $\alpha=0.036$ which is under a significance level of $0.05(0.036<0.05)$, thus $\mathrm{HO}$ is 
rejected. This means that there is an effect of the interaction between LMG textbooks and learning motivation on students' learning outcome.

\subsection{Discussion}

Based on the research findings, it seems important to use textbooks in LMG. The results revealed that manual LMG textbooks got superior learning outcome (average 78.4) compared to digital LMG textbooks (average 74.3). Excellent LMG textbooks are made in accordance with the character of the LMG materials. Manual LMG textbooks give students an opportunity to analyze the existing problems through learning literacy activities. According to Bar-tosova et al. (2015), using textbooks in teaching can improve learning outcome and attractiveness.

The implementation of textbooks is interesting and appropriate to increase the understanding and skills that are geospatial (spatial on earth). LMG is one source to know various learning media. The problems associated with media need to be solved by students through the study and analysis of strong literacy.

The importance of high motivation in learning LMG is also raised by Widartono (2011), who revealed that LMG is as a high productivity in the form of representation of the real world that communicates the reality (geographical phenomena) in an image to the user. The results are consistent with previous research conducted by Sulistiyawati (2011) that there is significant influence of learning motivation on students' achievement. Results of research conducted by Ridwan (2008) concluded that motivation in learning affects learning outcome. The group having high learning motivation obtains better learning outcome compared to low learning motivation.

Textbooks play a role in deciding the content and activities of the class, the use of textbooks is always in a position to be adapted, which is motivated by their own beliefs and experiences (Miguel, 2015). Manual LMG textbooks used in teaching students who have high learning motivation also produce high learning outcome. This means that the manual LMG textbooks correspond to LMG in learning, particularly for students who have high learning motivation.

\section{CONCLUSION}

Based on data processing and discussion of research findings, this study concludes that: 1). LMG learning outcome of students using digital and manual LMG textbooks differ significantly. LMG overall learning outcome of students who are taught by manual LMG textbooks is higher than the learning outcome of students who are taught by digital LMG textbooks. It can be concluded that the manual LMG textbooks have a better effect on learning outcome compared to digital LMG textbooks; 2) there are significant differences between students' LMG learning outcomes predisposed by high and low learning motivation. High learning motivation students get better grades than low learning motivation students, in both manual and digital LMG textbook; 3). there was an effect of textbooks and learning motivation towards learning outcome of LMG. The learning result is best for students who have high motivation in learning and are taught by manual LMG textbooks. Thus, it can be said that the learning outcome of LMG is influenced by the type of textbooks and students' motivation in learning.

\section{REFERENCES}

[1] Bartosova, I.K, Plovajkováb A, and Podneckác, T. 2015. Developmen of Reading Literacy Based on the Work of Textbooks (Workbooks). Procedia - Social and Behavioral Sciences. 171. 668 - 679.

[2] Degeng, INS 1997. Learning Strategy, Organizing Content with Model Elaboration. Malang: The Malang Teachers' Training College in cooperation with the publishing Bureau Educational Technology Professionals Association.

[3] Dick, W. \& Carey L. 2001. The Systematic Design of Instruction. Fifth Edition. Illinois: Scott \& Co. Publication.

[4] Joo, J.Y, Park. S, and Shin E.K. 2017. Students' Expectation, Satisfaction, and Continuance Intention to Use Digital Textbooks. Computers in Human Behavior. 69. 83-90.

[5] Marinkovic, S \& Eric M. (2014). The Problem of Value in a Textbook Procedia - Social and Behavioral Sciences. 128. 72 - 76.

[6] Miguel, N.M. 2015. Textbook Consumption in the Classroom Analyzing a Classroom Corpus. Procedia - Social and Behavioral Sciences. 198. $309-319$

[7] Milligan L.0, Tikly, L, Williams, T, Vianney, J. M, and Uworwabayeho A. (2017). Textbook Availability and Use in Rwandan Basic Education: A Mixed-Methods Study. International Journal of Educational Development. 54. 1-7.

[8] Mohammadi, M \& Abdi, H. 2014. Textbook Evaluation: A Case Study. Procedia - Social and Behavioral Sciences. 98. 1148-1155.

[9] Moore, K.D 2005. Effective Strategies Instructional, from Theory to Practice.New York: Sage Publications Inc.

[10] Reigeluth, C. M 1999. Instructional-Design Theories and Models; A New Paradigm of Instructional Theory.Volume II. New Jersey: Lawrence Erlbaum Associates, Publishers.

[11] Reigeluth C. M, Alison A. 2009. Instructional-Design Theories and Models, Volume III. New York: Routledge Publishing. Taylor \& Francis Group.

[12] Ridwan. 2008. Effect of Learning Model (Contextual VS Conventional) and Learning Motivation to Understand-ing Concepts Principle.(Dissertation). A graduate of the State University of Malang.

[13] Stone, R.W \& Baker-Eveleth, L. 2013. Students' Expectation, Confirmation, and Continuance Intention to Use Electronic Textbooks. Computers in Human Behavior. 29. 984-990.

[14] Sulistiyawati, RS 2011. Learning Biology Using Animation and Video Interactive Media Judging of Creativity and Student Motivation.Thesis Unpublished. Surakarta: Eleven University Graduate Program in March.

[15] Wiarton BS 2011. Optimal Utilization of Human Sensing as a Human Input Spatial Cognition. Annual Scientific Meeting (PIT) geographers Association of Indonesia (IGI). Ganesha Education University Singaraja. 